\title{
Using Proactive Maintenance Strategy for Sustainable Electric Power Production in Nigeria
}

\author{
Tekenah Bestmann $^{1^{*}} \quad$ Kingsley Orima ${ }^{2} \quad$ Anthony Odukwe ${ }^{3}$ \\ 1.Maintenance Department, Nigerian Agip Oil Company Ltd, Kwale-Delta State, Nigeria \\ 2. Faculty of Engineering, University of Nigeria, Nsukka, Enugu State, Nigeria
}

\begin{abstract}
An unpleasant turn of events would compel and prevail upon power plants owners and operators looking for alternative for keeping maintenance activities up and awake. Thus, causing a break away from outdated traditional system originally practiced in maintenance organizations, which affects operations in terms of costs and energy required for sustainable activity in the power production industry; via Generation, Transmission and Distribution. However, the only inevitably obtainable option as per organizational success in the power industry is through a substituent for a failure based system with success based strategy that is concerned with optimization of complex processes, systems or organization by developing, improving and implementing integrated systems of people, money, knowledge, information and equipment, central to manufacturing and production operations. A platform intended to deliver on plant (a) availability (b) reliability and (c) sustainability, which lead to reduced maintenance costs and increased profitability.
\end{abstract}

Keywords: maintenance management; strategy implementation, power sector, performance optimization DOI: $10.7176 /$ IEL/11-3-03

Publication date:October $31^{\text {st }} 2021$

\section{Introduction}

In many electric power plants, costs of maintenance takes larger chunk of operational costs in estimating income and expenditure for a given period of time, as a result to have maintenance to produce desired and intended result becomes a source of financial gains. Competitive environment in today's context would require that electric power plants try to sustain full production capabilities, while fully minimizing capital investment. Turbine is the most valued asset in a power generation plant, maintenance of turbine hence becomes a crucial part. Therefore, proper approach can help in reducing operation and maintenance costs and keep the power plant work efficiently, and ignoring the need for proper approach in maintenance can lead to system breakdown.

Good maintenance strategies can assist an organization locate ways to increase reliability and output, "Improving Machinery Reliability through Lubrication Management" where proper maintenance practices will be a hallowed sanctity. From the maintenance perspective, this involves optimizing equipment reliability i.e. availability, including prolonging the life of the equipment. Good knowledge operation and maintenance should deliver cost-effective production and should be the platform for astute management decision-making. Unfortunately, preventive maintenance activities in many power plants are poor in performance and thus do not deliver.

Maximum machinery performance is one of the major goals for electric power distribution system managers. To achieve the optimal minimal life cycle cost and maintenance optimization becomes crucial while meeting demands from customers and regulators. One of the fundamental objectives is therefore to relate maintenance and reliability in an efficient and effective way. Furthermore, this necessitates the determination of the optimal balance between preventive and corrective maintenance, which is the main problem addressed in this study. The balance between preventive and corrective maintenance is approached as a multi purpose optimization case, with the customer and maintenance costs in consideration

Efficient maintenance is obtained through reliability analysis for power system where reliability models solved with computers were developed, (Gaver et al 2004 and Cumming et al 2005). However, new tools and new demands on the electric power systems demand further development of methods, such as maintenance optimization routines. Methods to support cost-effective maintenance policies have been developed for electric power systems as presented in (Bertling, 2007) which presents a quantitative method for developing Reliability Centered Maintenance (RCM) plans. The resulting technique involves the comparison of different policies for maintenance and therefore the results provide not the optimal solution but the best solution from the selected policies. The question of finding an optimal maintenance solution is not new (Endrenyi et al, 2001; Hällgren and Öfverbäck, 2005).

However, the relation between maintenance, reliability and costs is not at completely ease and requirements from plant owners and customers, create needs and incentives for still newer methods to handle the maintenance in an effective and efficient way. It becomes important to identify a connection between component and system reliability performance where the system performance is measured for several load and supply points at a time. 


\section{Maintenance optimization methods}

Maintenance optimization is a method aimed at finding the optimal balance between preventive and corrective maintenance with respect to objectives. The objectives are assumed to be revenue and satisfied customers. Satisfied customers are important; otherwise, they will potentially buy their energy from other companies and/or cause increased regulation. The definition of maintenance optimization is the same as asset management because a good maintenance optimization supports asset management in all ramifications. From a reliability viewpoint the reason for maintenance is quite clear, that is to increase the reliability by means of improving tools. Another aspect of maintenance is to reduce risk, usually by inspection, risk reducing approach can be said to be a subgroup of the main objective (increase reliability), since it is aimed at identifying failure mode in an equipment. There are other objectives of maintenance such as appearance and worth of the maintained equipment. Appearance and worth does not necessarily correlate with reliability. Maintenance optimization started when preventive maintenance plans became a popular and a growing concept, and when operation research methods was applied to preventive maintenance plans. Condition monitoring improved the effect of the maintenance with the introduction of available computer systems, giving maintenance optimization ample opportunity to spread wider and faster (Jardine, 2007). Reliability Centred Maintenance (RCM), which was originally created for the aircraft industry, was introduced and applied and became a successful method for maintenance planning in electric power system.

\subsection{Corrective maintenance pathway}

Corrective maintenance is performed after fault recognition and is intended to put the component in a state in which it can perform a required function (SS-EN 13306:2001). The component is used until it fails again. Corrective maintenance may be considered as a last resort and might intuitively be considered as a failure of the maintenance organization performing it, but that is not necessarily the case. Corrective maintenance has its place in a sound maintenance strategy at least in the planning stage. Corrective maintenance might be the right approach for a component group given that resources are focused on other, possibly more important, assets. For equipment with random occurring instant failures corrective maintenance might be the only option. As mentioned above one might consider redesign of the system for these kinds of failures, but still it is quite likely that these failures might be worth "living with" while focusing on other areas with a better goal fulfilment.

\subsection{Preventive maintenance pathway}

The concept of preventive maintenance is to reduce failure probabilities by maintenance before failure or significant degradation occurs (SS-EN 13306:2001). This often translates into trying to avoid costs of corrective maintenance and other costs that translate to unexpected failures. Preventive maintenance can be divided into two groups:

\section{- $\quad$ Periodical maintenance; and}

- $\quad$ Condition based maintenance.

2.2.1 Periodical maintenance: is performed at regular intervals (no specific time). This is a good strategy in the case of a well identified ageing process for the component. The time intervals between the maintenance should be based on the expected time to failure with shorter intervals for the maintenance, than for the expected time to failure. Usually the periodic maintenance is based on time intervals from the OEM or policy on ground. By generalizing it can be stated that the original equipment manufacturer (OEM) is more interested in that the product does not fail during the warranty time than in the maintenance organization's costs. (This can however be addressed with techniques such as Life Cycle Cost (LCC) analysis in the procurement phase of equipment.) The company policies seldom consider different makes, usage and environment. A potential risk lies within the periodical maintenance if it is performed at these generalized time intervals. To maintain a component unnecessarily often introduces higher maintenance costs and risks for faults introduced by the maintenance activity (Hilber and Lindquist, 2003).

2.2.2 Conditioned based maintenance: is performed based on an estimate of the components condition. One of the simpler forms of condition based maintenance is to prolong the first service interval of a periodical maintenance routine, this is based on the assumption that new equipment is in better condition compared to older, i.e. methods based on measurements (diagnostics and inspections). Methods based on measurements present a wide variety of methods, partly depending on the component being investigated. When considering preventive maintenance actions and specifically replacement actions the cost of the action might seem high compared to the benefits of the replacement. But under certain circumstances the cost of doing maintenance earlier than necessary can be considered to correspond to the depreciation from the time of maintenance to the point in time considered to necessitate the maintenance activity.

\subsection{Reliability centered maintenance (RCM)}

This is a very systematic strategy with goals. It demand high skill from only few people and hence can be easily or quickly started. The basic focus is on uncovering all potential modes of failures and addressing these through 
the three actions of Preventive, Predictive and Default action. The process requires extensive analysis, through an FMEA of all equipment and is time consuming. The analysis is a time consuming activity, therefore the major problem associated with a conventional RCM process is that in the period of the study, there will be no benefit accrued and at times this can lead to loss of management support, and miss crucial recommendation (Rausand and Høyland, 2004).

\subsection{Total productive maintenance (TPM)}

The strategy that aims to empower individuals; best suited for effective operations i.e. operators and maintenance staff working together as a team to reduce waste, minimize downtime, improve product quality, and effectiveness of equipment. The goals are simple and measurable, the entire process is both system and people driven and training requirements are higher and this strategy is directed towards building a minimum level of competency across all employees. On the positive side, the strategy results in increased skill of all employees, greater participation and hence improved morale (Jetpack Institute of plant maintenance, 2006). And establish a clean schedule of total clean-up and PM to extend the plant's life span and maximize uptime; and emphasize carrying maintenance activity decently unlike what obtains in the Nigerian power sector as shown in figure 1 . The tasks involved include routine inspection, lubrication, adjustments, minor repairs, as well as the cleanliness and tidiness of work space (Endrenyi, 2005 and Brown, 2002).

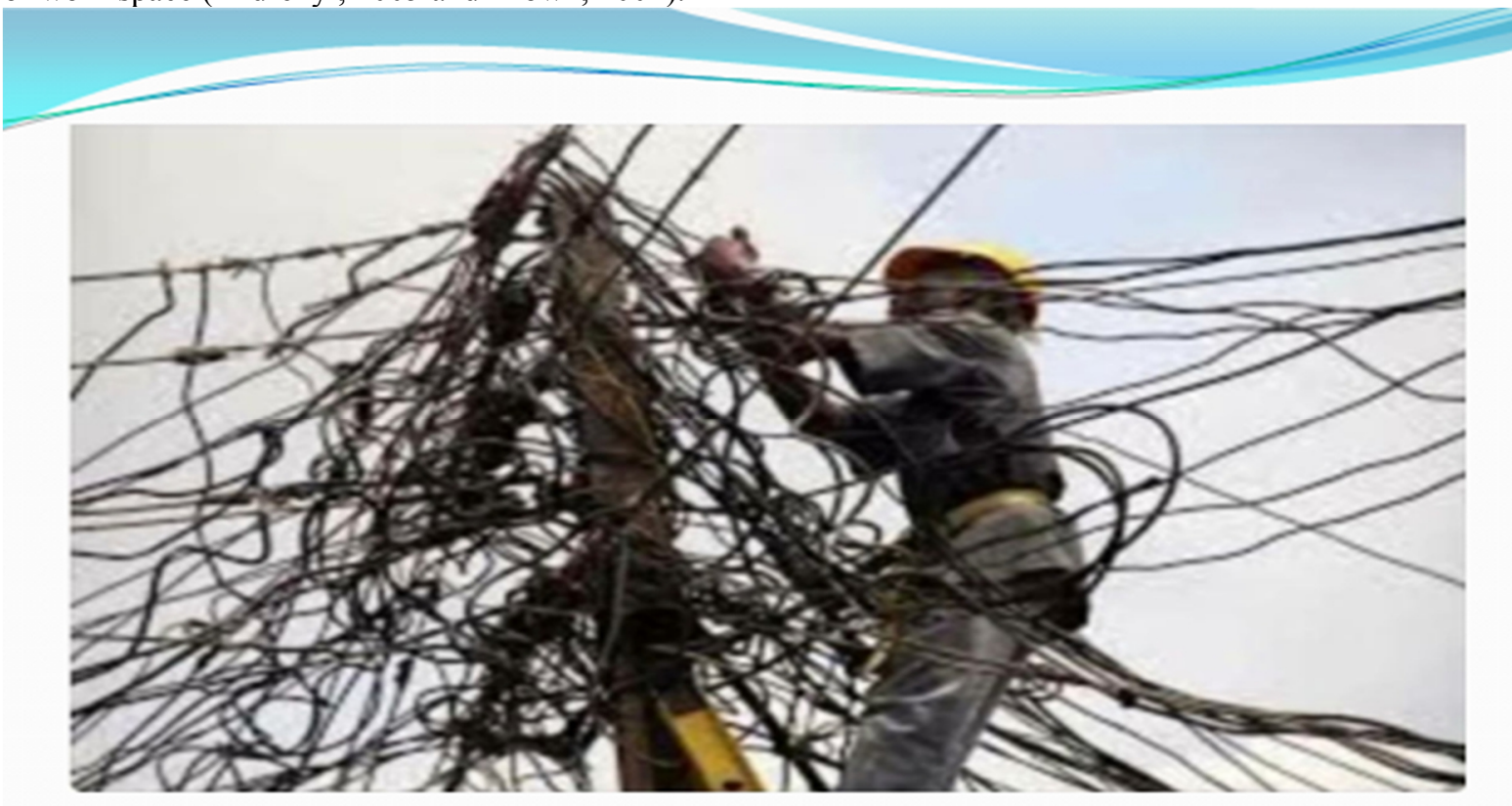

Figure 1: Untidy method of carrying out maintenance activity in the power sector (Distribution)

\section{Maintenance strategy in case study electric power stations}

The deregulation has led the distribution system managers' attention towards profit optimization. That is a shift from an engineering perspective: focusing on reliability and "good technical solutions", to a more business and profit orientated system. The illustration show a study performed at a case study power plant: Afam and Sapele power stations for circuit breakers in Figure 2. It seems like periodical maintenance is losing ground to condition based maintenance and RCM approaches. This is further illustrated with the distribution of maintenance activities in the power stations with: $5 \%$ corrective maintenance, $90 \%$ periodical maintenance, and $5 \%$ condition based maintenance (Gillander, 1997). Of course these values depend on power station's definition of the maintenance strategies, but it is possible to identify the trend, (Rausand and Høyland, 2004; Endrenyi, 2005). 


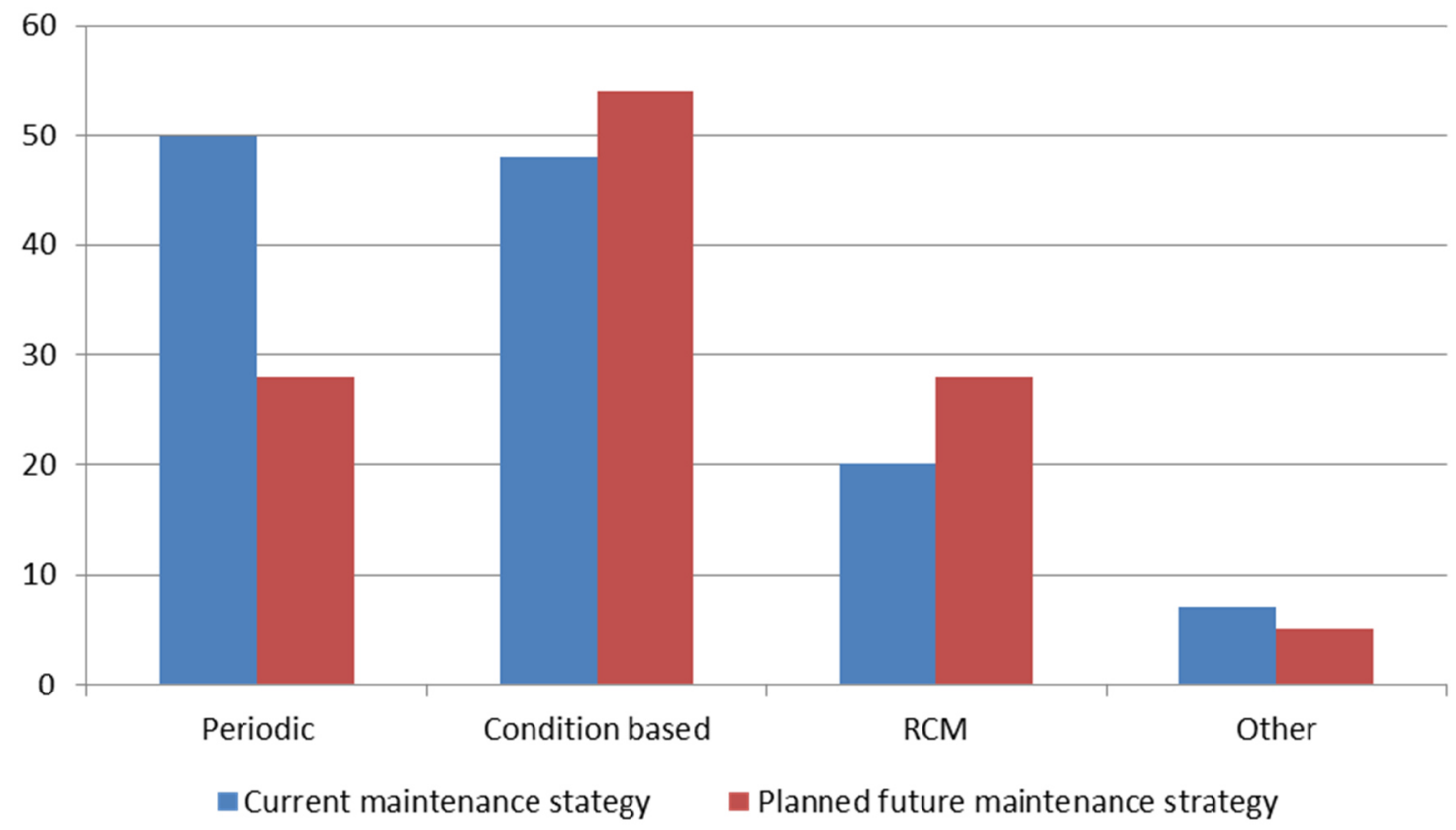

Figure 2: Current and planned maintenance strategies for power system.

\subsection{Common maintenance problems}

Some common problems for electric power stations are identified in (Hilber, 2005 and Bertling, 2007). Many of these problems have two aspects, i.e. it is important to create balance between the problem and its solution, which are costly and include some disadvantages or problems:

- Failures are often not analyzed to the extent that similar future failures can be prevented;

- Effective maintenance actions are made but without structure and clear relevance to organization objectives;

- Periodical preventive maintenance is performed unnecessarily often; maintenance is performed towards technical goals without economical considerations;

- Non-existent reasons for maintenance actions, it is crucial to know why the;

- Maintenance action is performed, without this knowledge it is hard to estimate the value of the maintenance action;

- Low visibility of maintenance strategy. If the effects of the maintenance activities are not clear for the organization it is hard to motivate the current strategy;

- Accepting manufacturer's recommendations without consideration of specific circumstances of the usage; does the manufacturer's maintenance goal coincide with the user? and

- Resistance towards new equipment for diagnostics that could improve the maintenance actions impact on system reliability (Hilber, 2005 and Gillander, 1997).

Anders (2000) opined that efficiency and effectiveness of equipment determines the performance of organizational productivity function as well as the level of success achieved in modern power industry. The market oriented competitive environment in electric utilities has forced many power plants to become more conscious of the role of maintenance management in enhancing their equipment performance and consequently improving the quality of their services, (Billiton and Allan, 1996). Good equipment maintenance practice which can improve the reliability of the power system maintenance has become the prominent issue for electric utilities. The use of optimum method for maintenance management practice can improve the overall effectiveness of the operations and maintenance of the power plant.

\subsection{Major production of power challenges in Nigeria}

The following are major critical challenges of the power sector responsible for the generation short-falls, transmission bottlenecks, and distribution problems in Nigeria.

- $\quad$ poor utilization of existing assets and deferred maintenance;

- delays in the implementation of new projects;

- lack of sustained, sound and practicable relationship between Federal government and other stakeholders, particularly, the Joint Ventures (JV) international oil companies and the Independent Power producers 
(IPP);

- inadequate power evacuation at newly completed and factionalized power plants;

- $\quad$ erratic supply of gas-domestic resources for power generation;

- vulnerable and overloaded existing transmission system;

- $\quad$ some sections of the National Grid are outdated with equipment in a state of poor and inadequate maintenance;

- there is a serious lack of required modern technologies or communication and monitoring of the generation, transmission and distribution infrastructures;

- $\quad$ poor technical staff recruitment, capacity building and training program; and

- inappropriate tariff that would enable the utility to get adequate funds to maintain and expand the infrastructure; etc. (Sambo et al, 2003).

To address these challenges, an innovative strategy is required for structured maintenance, most especially as energy generation, transmission and distribution in Nigeria for necessary development is a priority issue. The Figure 3, show identified problems on possible limiting factors. The graph shows that maintenance planning and spare-parts inventory management tops as the most influencing factors affecting the power industry performance.

RANKING OF FACTORS AFFECTING POWER PRODUCTION IN NIGERIA

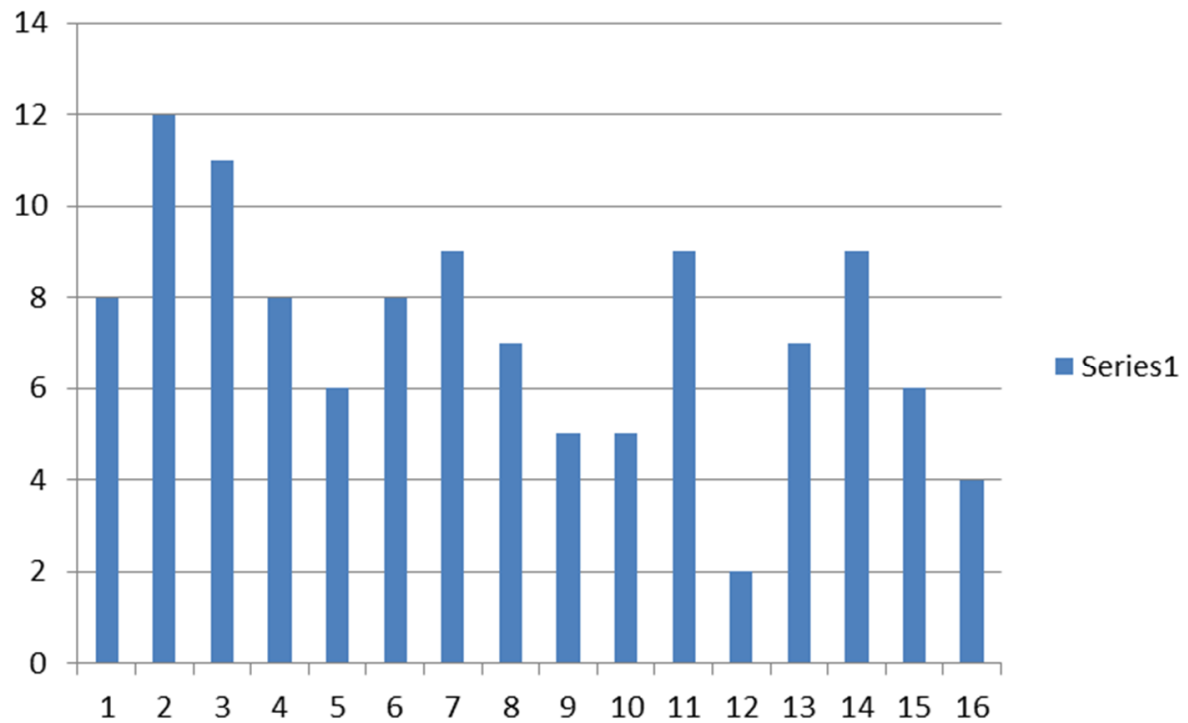

Figure 3: Factors affecting power production in Nigeria

1) Inadequate funding

2) Poor maintenance planning

3) Spare parts inventory

4) Management attitude

5) Manpower proactiveness

6) Manpower training

7) Government attitude

8) Contractors' attitude

9) Equipment vandalism

10) Drought
11) Inadequate gas supply

12) Wrong location

13) Non policy continuity

14) Limited automation

15) Energy mix technology

16) Competitiveness

\subsection{Reliability assessment techniques}

Reliability is the ability to perform required function under given conditions for a given time interval (SS-EN 13306:2001) often expressed as a probability. A term that is closely related to reliability is availability. Availability further includes the concepts of maintainability and the maintenance supportability SS-EN 13306: (2001) and is generally expressed as the ratio of available time (mean time to repair-MTTR) divided by total time (mean time to repair-MTTR plus mean time to failure-MTTF). One importance sought after is the calculation of reliability and availability as a radical tool utilized in order to estimate the expected availability of systems as well as other system or component measures.

\subsection{Best Practices in maintenance management}

These enable an industry to achieve a competitive advantage over its competitors, and include the following: 
Computerized maintenance management system-CMMS; financial optimization; work flow and control; and continual improvement attitude.

3.4.1 Work flows and controls (SAP)

A work-order procedure should be used to initiate, track and record all maintenance activities. The process will start as a request that needs approval and once approved, the work order is planned, then scheduled, performed and finally recorded (Eti et al, 2006). All the maintenance activities are tracked through the work system. At least $80 \%$ of all maintenance work should be planned on a weekly basis: the scheduled compliance should be at least $90 \%$ on a weekly basis. Maintenance management systems in most electric power industries are so complex as to require computerizing the collection, processing, and analysis of the data. The computerized maintenance management system (CMMS) software manages the functions of preventive maintenance (PM) and provides support for some excellent practices.

\subsubsection{Financial optimization}

This statistical technique combines all of the relevant data about an asset, such as the costs of down time, maintenance, lost efficiency or poor-quality end product. It then assesses the data against financially optimized decisions, such as when to take the equipment off-line for maintenance, whether to repair or replace an asset, and how many critical spare-parts should be immediately available. Anders (2000) stated that financial optimization requires accurate data: making the associated decisions incorrectly could have a devastating effect on an industry's competitive position.

3.4.3 Continual improvement

Continually seeking for better methods of accomplishing a task is characterized by determining incremental as well as radical improvements to existing processes. Focusing on existing processes differentiates continual improvement from other approaches, such as re-engineering, which disregards existing procedures and develops new ways for accomplishing the task.

A continual improvement as part of asset care is an ongoing evolution that includes continually looking for the 'little things' that can make an organization more competitive. One of the key tools for achieving continual improvement is best practice benchmarking, which examines the maintenance process presently employed and compares it with those in organizations that are world leaders in this respect, and so highlight the changes necessary to improve the process (Eti et al, 2006).

\section{Computerized maintenance management system (CMMS)}

The management and supervision of operational activities involves a flow of data, which can be most easily managed when consistent, meaningful information is readily available to all parties-CMMS. This depends on the ready access to all information on design, construction, manufacturing, spare parts, skilled manpower resources and operations and maintenance histories. The CMMS which is supported by System Application Production (SAP) can be implemented to achieve the management of such data.

The importance of the CMMS cannot be over emphasized in weighing and considering the operations of the electric power industry. The CMMS is a central component of many industries maintenance department and it can offer support on variety of levels in the organizational hierarchy. CMMS are computer based software programs used to control work activities and resources, as well as to monitor and report work execution. CMMS are tools for data capture and analysis, its major features includes processing of maintenance data to give useful information on which management decisions are based. This information can be analyzed or evaluated with respect to previous result, such that performance over a period of time can be assessed.

The power plants managers will therefore find it convenient in making use of the available data to plan for present and future goals. There is also the advantage of printing out this information in a hard copy at any desired time. Other useful information, such as work done in maintenance department and its Total Cost (TC), list of jobs worked on during a period and inventory taking can be presented in a manner that will greatly ease both the technical and administrative task of maintenance. Through networking of the system information can be passed efficiently between the maintenance department and the organization's management.

The data processed on CMMS can be stored permanently or retrieved much faster, for future use or modifications. It can also be used for maintenance planning and scheduling, coordinating people, controlling resources and cost of maintenance functions. The information is intended to help maintenance workers do their jobs more effectively (e.g. determining which machines require maintenance and which store rooms contain the spare-parts needed) and to help management make informed decisions (e.g. calculating the cost of machine breakdown, repair versus preventive maintenance for each machine, possibly leading to better allocation of resources). CMMS data may also be used to verify regulatory compliance.

\subsection{Asset management of electric power systems}

Asset management and maintenance optimization are two related things in industrial engineering. Ultimately, maintenance optimization is a tool set within wider concept of asset management. In the power production industry 
there are several things that can be termed an asset especially as written below:

- Capital;

- Equipment and premises (physical assets);

- Employees;

- Customer base; and

- Corporate structure.

Asset Management in the electric power systems mainly deals with physical assets with a focus towards heavy equipment (Hilber, 2005). However, there are other assets that are inclusive in asset management considerations, involved as costs or constrains at work with asset management. The primary assets are assumed to be the physical ones. Usually these physical assets have an expected life of more than one year, above 20 years for electric power equipment and represent a big turnover (Jardine, 2007; Billiton and Allan, 1996). The aim of asset management is to cater for physical assets in an optimal way in order to fulfil an organizations goal and same time considering risk involved. The goal is maximum profit at an acceptable risk, and asset management becomes a method to achieve this through handling the physical assets. A number of actions are identified that are closely associated with asset management:

- Acquire;

- Maintain;

- Dispose;

- Replace; and

- Redesign/Rebuild.

These actions are what the power plant asset manager can use to align the assets with the goal fulfilment. The task is not an easy one; where and when should the actions take place and which of the actions is the best one for every specific component? All the actions are related to each other, i.e. a replacement consists of a disposal and an acquisition. In the acquisition phase redesign is considered and afterwards the equipment has to be maintained. Risk, as probability for failure multiplied with consequences, is one important aspect of asset management. Asset management methods are often referred to as the way to keep the risk at a constant level while downsizing cost (maximizing profit). This is achieved by a better utilization of the available asset i.e. by performing the best actions at the best possible time. In order to do this, different methods and systems are used.

The concept of asset management can be derived from choosing the right profit-risk level. To choose the right level of risk and profit is significant as a second level, after a cost minimization at constant risk. Figure 4, shows the classical problem, profit versus risk, which has to be considered. By the identification of the goal of asset management to handle physical assets in an optimal way in order to fulfil an organiza- tion goal with consideration of risk at same time, maintenance has to be put in its right context. A context that clarifies the need of maintenance optimization and points out that all aspects of asset management has to be considered in the optimization.

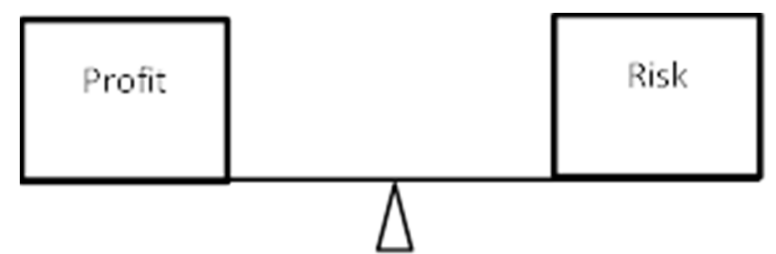

Figure 4: Profit versus risk

\section{Conclusion}

The study suggests maintenance optimization pathway with a dual functional approach for power systems. The pathway can be used for development of a maintenance policy that improves the utilization of maintenance resources. It has been shown that with a diversification of the maintenance between components, it is possible to decrease total cost of maintenance while increasing average reliability for consumption.

This optimization is built on component reliability performance indicators, which makes a tool for maintenance prioritization that can be useful. For large systems the optimization and calculation of indices are demanding on both the data and the calculation aspect. However, if data intense reliability calculations are carried out, a good foundation for asset management decisions is produced. The applicability of the optimization and component reliability key performance indicators are found in case study plants from gathered genuine data, indicating that the methods can be practically implemented.

A consequence of using existing maintenance methods is that components of the same type should sometimes be maintained differently due to their location in the system, and on how they are operated. This is a result from a maintenance policy that moves resources to the most important components. In this context, it is important to point out that maintenance actions considered can be of both increased and decreased maintenance, enabling the optimization process to diversify the maintenance. 


\section{References}

D. P. Gaver, F. E. Montmeat and A. D. Patton (2004) "Power System Reliability-I Measures of Reliability and Methods of Calculation," IEEE Transactions on power apparatus and systems, $7^{\text {th }}$ ed. vol. 83, pp. 727

D. J. Cumming, F. E. Montmeat, A. D. Patton and J. Zemkowski (2005) "Power System Reliability-II Applications and a Computer Program," IEEE Transactions on power apparatus and systems, vol. $9^{\text {th }}$ edition 84, pp. 636,

L. Bertling, (2007) "Reliability Centred Maintenance for Electric Power Distribution Systems", PhD thesis, KTH, Dep. of Electric Power Engineering, KTH, Stockholm, ISBN 91-7283-345-9,

P. Hilber (2005) "Component reliability importance indices for maintenance optimization of electrical networks", Licentiate thesis, School of Electrical Engineering, KTH, Stockholm, Sweden, ISBN 91-7178-055-6.

J. Endrenyi, S. Aboresheid and R. N. Allan (2001) "The present status of maintenance Strategies and the impact of maintenance on reliability". IEEE Transactions on power systems, vol 16, no. 4,.

B. Hällgren and P. Öfverbäck" (2005): Some Practical Aspects on Maintenance Interval Optimization”, Proc. of the 12th Inter-Ram Conf. for the Electric Power Industry, Baltimore, USA,

SS-EN 13306:2001 "Maintenance terminology", Swedish standard 2001, 1st edition

P. Hilber and T. Lindquist (2003) "The maintenance process", in Swedish 2003, A-ETS/EEK-0301 KTH, Stockholm, Sweden.

L. Gillander, 1997,"Approaches to maintenance”, in Swedish, Vattenfall, Sweden, UE 1991/2, and ISSN: 11005130

M. Rausand and A. Høyland, 2004, "System Reliability Theory", 2nd ed., John Wiley \& Sons, Hoboken, New Jersey, USA, ISBN: 0-471-47133-X.

A. K. S. Jardine, 2007, "Maintenance, Replacement and Reliability", $8^{\text {th }}$ ed. Pitman Publishing, Toronto, Canada ISBN: 0273316540.

J. Endrenyi, 2005, "Reliability Modeling In Electric Power Systems" Wiley and Sons, ISBN: 0- 471-99664-5.

R. Billiton and R. N. and Allan, 1996, "Reliability evaluation of power systems" 2nd ed. Plenum Press, New York.

G. Anders, 2000, Probability concepts in electric power systems", John Wiley \& Sons, USA, ISBN: 0-471-502294.

R. Brown, 2002, "Electric power distribution reliability" Marcel Dekker Inc., ISBN: 0-8247- 0798-2.

Sambo, A, Garba, B and Gaji, M (2003) "Electricity Generation and the present Challenges in Nigeria power sector" Energy Commission of Nigeria, Abuja

Jetpack Institute of plant maintenance (1996) "Achieving autonomous maintenance in difficult setting as strategy" Available from: http //www.maintenanceresources.com (2006, April 19). 16.

Eti et al, 2006, "Reducing the cost of maintenance (PM) through adopting a proactive reliability focused culture", www.elsevier.com/locateepenergy. 